\title{
LAS NORMAS ADMINISTRATIVAS Y EL SISTEMA DE FUENTES*
}

\section{EDUARDO CORDERO QUINZACARA**}

RESUMEN: En esta investigación se analiza, desde una perspectiva general, la naturaleza, fundamentos y efectos de las diversas normas que emanan de los órganos de la Administración del Estado, con el objeto de establecer un marco general para comprender la forma en que se integran en nuestro ordenamiento jurídico. El autor sostiene que el análisis debe centrarse en los elementos sustantivos de estas normas antes que en la nomenclatura con la cual son denominadas. A su vez, afirma que las normas administrativas solo pueden ser reconducidas a dos categorías (reglamentos y circulares), criterio que también aplica a las facultades de interpretación que la ley atribuye a diversos órganos de la Administración.

PALABRAS CLAVE: Normas administrativas - ordenamiento jurídico reglamentos - circulares.

\section{AdMinistrative Norms AND THE SOURCES OF LAW SySTEM}

ABSTRACT: This research analyzes from a general perspective the nature, foundations and effects of the different norms that arise from the State controlled agencies, in order to set a general framework to comprehend the way in which they are integrated into our legal system. The author sustains that the analysis must focus in the substantial elements of these norms instead of the nomenclature with which they are named. He also states that administrative norms can only be classified in two categories: regulations and written notices, criteria that can also be applied to the faculties of interpretation that the law confers to different State controlled agencies.

Este trabajo es parte de una investigación financiada por FONDECYT referida al proyecto El ordenamiento juridico chileno y el nuevo sistema de fuentes, № 1080619.

** Abogado, Doctor en Derecho por la Universidad Carlos III (España), Profesor de Derecho Administrativo de la Pontificia Universidad Católica de Valparaíso (Chile). Correo electrónico: eduardo.cordero@ucv.cl.

Fecha de recepción: 29 de marzo de 2010.

Fecha de aprobación: 12 de julio de 2010. 
KEY WORDS: Administrative Norms - Legal System - regulations written notice.

\section{INTRODUCCIÓN}

El ordenamiento jurídico constituye un conjunto plural y complejo de normas que demanda de sus operadores criterios ciertos para determinar la forma o modo que se han de aplicar cada una de ellas, especialmente cuando se produce una colisión o conflicto. Ahora bien, uno de los primeros aspectos que se debe resolver para dar respuesta a la pregunta capital sobre el derecho aplicable, es determinar la naturaleza, sentido y función que cumplen cada una de estas normas, que van desde la Constitución hasta llegar a las normas de menor jerarquía.

Desde un tiempo a esta parte, las diversas fuentes positivas han sido consideradas por la doctrina y la jurisprudencia como un tema capital, lo cual ha llevado a un acabado y profundo análisis de cada una de ellas. Esto ha ocurrido, en primer término, con la Constitución, de la cual se han extraído una cantidad importante de consecuencias normativas que la han colocado en el centro del sistema y de la discusión jurídica. Algo similar, aunque con una data mayor, se ha presentado con la ley, la cual ha dominado el sistema de fuentes durante el siglo XIX y buena parte del pasado siglo. Y qué podemos decir de la importancia que han adquirido otras fuentes, como los tratados internacionales, la legislación delegada, las normas reglamentarias, etc. Todas y cada una de ellas reconocen un abundante aparato bibliográfico destinado a desentrañar el sentido de cada una de estas normas o fuentes en el marco del orden constitucional vigente.

Sin embargo, la extrema preocupación por el estudio de estas fuentes no guarda la debida proporción en relación a un número considerable de normas que se mueven en un nivel inferior y que no tienen, al parecer, la dignidad que se reconoce a las que se ubican en los pisos superiores del sistema. Nos referimos a un conjunto de normas o disposiciones que se dictan al interior de todo el complejo orgánico que integra la Administración del Estado, constituyendo una verdadera masa multiforme difícil de poder encasillar dentro de las categorías tradicionales, pero que llenan las páginas de nuestro Diario Oficial llegando a constituir las normas de referencia obligada de los funcionarios, quienes muchas veces están más a lo que establece una circular o instructivo antes que la Constitución y las leyes.

El estudio de esta materia nos plantea, de entrada, dos problemas básicos. En primer término, nos encontramos con una falta de uniformidad en la nomenclatura, lo cual lleva a una diversidad notable en las denominaciones (circulares, instructivos, decretos supremos, resoluciones, 
programas, planes, ordenanzas, etc.). En segundo lugar, existe una gran dificultad para establecer la naturaleza jurídica de estas normas administrativas, cuestión que resulta capital para determinar su ubicación en el sistema de fuentes del derecho y la forma cómo se relaciona con otras normas.

En tal sentido, comenzaremos con el primero de estos puntos, con el objeto de sentar un criterio más o menos uniforme que permita identificar claramente cada uno de estos tipos normativos, para luego determinar la naturaleza jurídica de los mismos y la forma como se insertan en el ordenamiento jurídico. Además, dentro de esta materia queremos analizar la situación que se presenta con las facultades interpretativas que se atribuye a diversos órganos de la Administración.

\section{1) UNA DISTINCIÓN BÁSICA: FORMA Y CONTENIDO}

\section{1) CONSIDERACIONES GENERALES}

Un primer paso que se debe dar en este estudio dice relación con una distinción básica que debemos hacer al momento de establecer la naturaleza de las normas administrativa. Esta dice relación con la confusión que normalmente se produce entre la forma que adopta el acto y la naturaleza jurídica del mismo. Es muy habitual que se le atribuya cierta sustantividad a un acto, a pesar que sus elementos constitutivos son esencialmente formales, independiente al contenido del mismo.

Esto ocurre habitualmente con los decretos supremos y las resoluciones. Ambas habitualmente se presentan como tipos de normas o actos administrativos, siendo que solo constituyen la forma que adopta la expresión de voluntad de determinadas autoridades en el ámbito jurídico para ejercer sus competencias, lo cual es independiente al contenido del mismo. Así, es perfectamente posible que un decreto supremo o una resolución contengan normas o actos administrativos del más diverso carácter: nombramiento de funcionarios, aplicación de medidas disciplinarias, autorización de gastos, otorgamiento de beneficios económicos, etc.

En tal sentido, el artículo 35 de la Constitución daría cuenta de lo señalado al establecer una de las formalidades que debe cumplir un decreto supremo y la posibilidad de que estos puedan ser objeto de delegación de firma. Al efecto, dispone en su inciso $1^{\circ}$ que "Los reglamentos y decretos del Presidente de la República deberán firmarse por el Ministro respectivo y no serán obedecidos sin este esencial requisito". Por su parte, en el inciso $2^{\circ}$ señala que "Los decretos e instrucciones podrán expedirse con la sola firma del Ministro respectivo, por orden del Presidente de la República, en conformidad a las normas que al efecto establezca la ley". La interpretación tradicional de esta disposición era entender que los decretos supremos tenían como condición esencial la firma del Presidente de la Repú- 
blica y del ministro o ministros respectivos, pero estaba la posibilidad de que estos se pudieran expedir con la sola firma de los ministros de Estado en caso que el Presidente hubiese hecho una delegación de firma. Esta interpretación fue revisada por el Tribunal Constitucional en la sentencia Rol No 153, de 25 de enero de 1993, poniendo atención en el cambio de redacción que tenía el inciso $1^{\circ}$ respecto del inciso $2^{\circ}$ : el primero habla de "reglamentos y decretos", mientras que el segundo se refiere a "los decretos e instrucciones".

Para el Tribunal Constitucional el Constituyente habría hecho una clara distinción entre los requisitos de forma que deben tener los reglamentos, los decretos y las instrucciones, de tal manera que los decretos e instrucciones pueden expedirse con la sola firma del ministro respectivo "por orden del Presidente de la República" y previa autorización legal, cuestión que no ocurre con los reglamentos, que han sido excluidos de la posibilidad de la delegación de firma y necesariamente deben ser suscritos por el Presidente de la República y además, por el ministro respectivo ${ }^{1}$. Por su parte, el Tribunal hace suya una clasificación clásica formulada por la doctrina y que distingue entre decretos supremos reglamentarios y simples decretos supremos, para hacer esta interpretación del artículo $35^{2}$. Sin embargo, cabe señalar que se trata de una distinción que tiene por objeto separar, por un lado, la competencia normativa del Presidente de la República ejercida a través de su potestad reglamentaria, respecto de las demás competencias que también han de requerir su expresión jurídica a través de estos decretos, por lo cual carece de todo contenido dogmático relevante, salvo esta limitación de carácter formal que ha hecho el Tribunal Constitucional en la sentencia ya citada. Ahora bien, lo más relevante de esta norma y su interpretación es entender que cualquiera sea la competencia del Presidente de la República, esta se ejerce jurídicamente a través de decretos supremos. Dicho en otros términos, el Presidente se expresa en el mundo jurídico a través de decretos supremos, que son el vehículo formal que le permite dictar normas, nombrar y destituir funcionarios, destinar e invertir los recursos públicos, otorgar indultos, etc. En buenas cuentas, el decreto supremo es un continente que puede abarcar los más diversos contenidos, porque solo constituye una forma o procedimiento que tiene el Presidente para ejercer las atribuciones y competencias que le atribuye la Constitución y las leyes.

¿Qué sucede con las resoluciones? A este respecto el inciso $3^{\circ} \mathrm{del}$ artículo $3^{\circ}$ de la Ley No 19.880 (en adelante LBPA) establece que los actos administrativos tomarán la forma de decretos supremos y resoluciones.

Considerandos $15^{\circ}$ y $16^{\circ}$.

Véase considerando $5^{\circ}$ de la sentencia citada. En tal sentido, se puede consultar Silva CimMA, Enrique (2009). Derecho Administrativo chileno y comparado. Introducción y fuentes, $5^{\mathrm{a}}$ edición, Santiago: Editorial Jurídica de Chile, p. 213. 
Acto seguido nos señala que el decreto supremo "es una orden escrita que dicta el Presidente de la República o un Ministro 'Por orden del Presidente de la República', sobre asuntos propios de su competencia" (inciso $4^{\circ}$ ), mientras que "las resoluciones son los actos de análoga naturaleza que dictan las autoridades administrativas dotadas de poder decisión" (inciso 50). Por lo tanto, debemos entender, en principio, que los decretos supremos solo pueden contener actos administrativos que emanen del Presidente, pues todos los demás actos administrativos dictados por otras autoridades de la Administración del Estado tendrán la calidad de resoluciones, como ocurre con los ministros, subsecretarios, intendentes, gobernadores, jefes de servicio, contraloría, etc.

El problema que se nos presenta ahora es tratar de determinar si el artículo $3^{\circ}$ LBPA tiene un alcance general respecto de forma y el procedimiento que deben seguir todos los actos formales de la Administración, incluidos las normas y reglamentos; o debemos entender que se aplica a una categoría restringida de actos administrativos, esencialmente aquellos actos de aplicación que no tienen carácter normativo. No olvidemos que el concepto de acto administrativo constituye el eje central sobre el cual se construye todas las normas contenidas en la LBPA: principios, procedimientos, etapas, efectos, extinción, silencio, etc. Por tal razón, el alcance que se le puede dar a este concepto legal es determinante en cuanto a su ámbito de aplicación.

Bien es sabido que la LBPA sigue un concepto tradicional de acto administrativo, que recoge los elementos de la concepción autoritaria y pandentista, señalándonos que "para efectos de esta ley se entenderá por acto administrativo las decisiones formales que emitan los órganos de la Administración del Estado en las cuales se contienen declaraciones de voluntad, realizadas en el ejercicio de una potestad pública" (inciso $4^{\circ}$ artículo $3^{\circ}$ ), y luego complementa esta definición indicando que "constituyen, también, actos administrativos los dictámenes o declaraciones de juicio, constancia o conocimiento que realicen los órganos de la Administración en el ejercicio de sus competencias" (inciso $6^{\circ}$ artículo $\left.3^{\circ}\right)^{3}$.

La mayor parte de la doctrina se ha inclinado por entender que el concepto de acto administrativo excluye a los reglamentos, por lo menos desde una perspectiva dogmática, dada la diferencia cualitativa que existe entre uno y otro acto: el acto administrativo debe someterse plenamente al bloque de la legalidad, mientras que el reglamento integra dicho blo-

3 Véase Pierry Arrau, Pedro (2007). "Concepto de acto administrativo en la Ley de Procedimiento Administrativo”, en VV. AA: Acto y Procedimiento Administrativo, Segundas Jornadas de Derecho Administrativo, Valparaíso: Ediciones Universitarias, pp. 71-80, y Cordero Quinzacara, Eduardo (2007). "La eficacia, extinción y ejecución de los actos administrativos", en VV. AA: Acto y Procedimiento Administrativo, Segundas Jornadas de Derecho Administrativo, Valparaíso: Ediciones Universitarias, pp. 109-130. 
que y constituye un marco de validez de los actos administrativos ${ }^{4}$, sin embargo, tampoco excluyen de forma radical la posibilidad de utilizar un concepto amplío, que comprenda a los reglamentos y lo contratos administrativo, y otro más estricto, limitado a los actos administrativos propiamente tales 5 .

Ahora bien, debemos tener presente que esta discusión se presenta en el plano doctrinal, el cual necesariamente debe enfrentarse con el dato positivo que entrega la ley, en este caso la LBPA, la que daría a entender que sus disposiciones comprenden no solo a los actos administrativos stricto sensu sino también a los reglamentos. Así se puede desprender del concepto que entrega el artículo $3^{\circ}$ inciso $2^{\circ}$, pues los reglamentos son declaraciones de voluntad que se dictan en ejercicio de una a potestad pública, aunque con efectos permanentes y generales. A su vez, y esto es casi determinante, los artículo 45 y 48 LBPA distingue claramente actos administrativos y normas. En primer término, nos señalan que los actos administrativos pueden ser de efectos individuales o pueden afectar a un número indeterminado de personas (actos administrativos generales). En el primer supuesto el acto se notifica (artículo 45 LBPA), mientras que en el segundo caso el acto debe ser publicado en el Diario Oficial para que se produzca sus efectos, como una licitación o concurso público (artículo 48 letra b). Por su parte, los actos administrativos que contengan normas de general aplicación siempre deben publicarse (artículo 48 letra a), y las normas generales que emanan de los órganos de la Administración son, por regla general, reglamentos. Cabe señalar que esta ha sido la posición compartida por nuestra doctrina ${ }^{6}$.

Esto nos permite afirmar que las normas contenidas en los incisos $4^{\circ}$ y $5^{\circ}$ del artículo $3^{\circ}$ LBPA tienen un alcance general respecto de todos los actos formales de los órganos de Administración del Estado. En buenas cuentas, cualquiera sea la naturaleza de estos actos, necesariamente deberán expresarse bajo la forma de decretos supremos o resoluciones. En

4 Véase Santamaría Pastor, Juan Alfonso (1991). Fundamentos de Derecho Administrativo, Madrid: Ramón Areces, pp. 720-726; Martín Retortillo, Lorenzo (1963). "Actos administrativos generales y reglamentos. Sobre la naturaleza de la convocatoria a oposiciones”, Revista de Administración Pública, No 40, pp. 225 y ss.; Leguina Villa, Jesús (1966). "Legitimación, actos administrativos generales y reglamentos. El valor normativo de las disposiciones organizatorias", Revista de Administración Pública, No 49, pp. 193 y ss.; Meilan Gil, José Luis (1967). La distinción entre norma y acto administrativo, Madrid: Escuela Nacional de Administración Pública. En Chile se puede consultar Pierry (2007) 71-80, en donde se puede encontrar aspectos relevantes sobre la discusión.

5 Véase Gordillo, Agustín (1984). Teoría General del Derecho Administrativo, Madrid: Instituto de Estudios de Administración Local, pp. 278-282. Pierry (2007) 76. 
principio, no hay otra posibilidad, salvo que la ley expresamente lo señale, como ocurre con los decretos alcaldicios o los decretos universitarios ${ }^{7}$.

En definitiva, queremos reafirmar la idea de que un decreto supremo o una resolución administrativa no tienen una naturaleza jurídica predeterminada, pues esta va a depender de su contenido, pudiendo ser reglamentos o actos administrativos en sentido estricto.

\section{2) DECRETO SUPREMO Y EL "PRINCIPIO DE LA PRIMACÍA DE LA REALIDAD” SEGÚN EL TRIBUNAL CONSTITUCIONAL}

A pesar de lo expuesto, existe en nuestra jurisprudencia la tendencia de entender que el concepto de decreto supremo sería de carácter sustantivo y no meramente formal, como ha ocurrido en un par de sentencias del Tribunal Constitucional.

El problema se ha planteado a propósito de normas administrativas dictadas por autoridades inferiores (ministros de Estado), pero bajo la forma de resolución. En este caso, se debe tener presente que el Tribunal solo tiene competencia para pronunciarse sobre la constitucionalidad de los decretos supremos (artículo 93 No 16 de la Constitución), mas no respecto de los actos que son de competencia de otras autoridades de la Administración. No olvidemos que los decretos supremos pueden ser dictados por el Presidente de la República o por sus ministros "por orden del Presidente de la República”.

En la causa Rol No 591 de 2008, la cuestión planteada decía relación con la eventual inconstitucionalidad de la Resolución Exenta $N^{\circ}$ 584, del Ministerio de Salud, del 1 de septiembre de 2006, la cual aprobaba las "Normas Nacionales sobre Regulación de la Fertilidad", es decir, se trata de una norma que no es un decreto supremo y que, por tanto, no está dentro de la esfera de competencia del Tribunal Constitucional. Sin embargo, al momento de conocer sobre esta materia, este órgano se planteo la posibilidad de "recalificar los actos administrativos como una forma de atraerlos a la esfera de su competencia" ${ }^{8}$. Es así como sostiene que "[...] la calificación jurídica de un acto administrativo determinado [...] es, sin duda, un elemento intrínseco de la competencia que la Carta Fundamental le ha conferido para velar por el imperio, formal y sustantivo, de sus valores, principios y normas. Sostener la tesis contraria resulta absurdo, desde que presupone excluir del examen constitucional aludido cualquier norma que, sobre la base de la propia nomenclatura utilizada, decida sustraer el propio órgano sometido al control referido -cualquiera sea este, la cir-

\footnotetext{
7 Véase artículo 12 LOC No 18.695, de Municipalidades. Respecto de las Universidades Públicas, sus Estatutos Orgánicos establecen que su máxima autoridad dictará los actos bajo la forma de decreto universitario.

$8 \quad$ Considerando $10^{\circ}$, Sentencia Rol No 591, de 11 de enero de 2007.
} 
cunstancia o el motivo invocado- aun cuando dicha norma abarque materias que, precisamente, el Constituyente ha querido someter al control de esta Magistratura" . Posteriormente analiza las normas legales sobre la materia y los diversos conceptos que entrega la doctrina, para llegar a sostener que la interpretación constitucional permite recurrir al principio de primacía de la realidad por sobre el nominalismo para desentrañar la verdadera naturaleza jurídica de un acto y, consecuentemente, los requisitos para su validez, o para precisar el genuino sentido de una norma ${ }^{10}$.

En definitiva, el Tribunal llega a la conclusión que la resolución impugnada es de carácter reglamentario. Más aún, señala que se trataría de un decreto supremo reglamentario o "reglamento supremo"11, razón por la cual afirma que dicha resolución "[...] reúne los elementos configurativos de un decreto supremo reglamentario, pero sin cumplir con las exigencias que la Constitución ha previsto para que sea tal". Abona su posición señalando que "[...] ese acto administrativo contiene un conjunto de normas; cuyo alcance es nacional o de aplicación general a todos los destinatarios de ellas; y dotadas de carácter permanente, es decir, que no agotan o pierden vigencia por su aplicación en un caso determinado. Sin embargo, tal Resolución Exenta carece de las demás exigencias que la Constitución contempla para los decretos supremos reglamentarios, porque fue dictada por la ministra de Salud, en circunstancias que hacerlo se halla prohibido, pues correspondía que fuese suscrita por la Presidente de la República y, además, debió ser sometida previamente al trámite de toma de razón en la Contraloría General de la República, atendida su naturaleza esencialmente reglamentaria”. Por lo tanto, el Tribunal señala que "habiéndose omitido estos dos requisitos esenciales para la formación válida de un reglamento, fuerza es concluir que la Resolución Exenta No 584 quebranta la Constitución, en su aspecto formal, lo que así será declarado por este Tribunal"12.

De la lectura de esta sentencia se puede apreciar claramente que hay una suerte de identificación entre reglamento y decreto supremo. La conclusión del Tribunal sobre este punto parece ser clara: todo reglamento debe ser aprobado por decreto supremo y no cabe, a este respecto, la delegación de firma. Esto constituye, en nuestra opinión, un error de envergadura, pues si bien el Presidente de la República dispone de una potestad reglamentaria otorgada directamente por la Carta Fundamental (artículo 32 No 6), no es posible negar que el legislador también ha atribuido la potestad de dictar normas a otros órganos de la Administración, tanto central como descentralizada. Así ocurre con los ministerios, subsecreta-

Considerando $13^{\circ}$, el destacado es nuestro.

Considerando $26^{\circ}$.

Considerando $30^{\circ}$.

Considerando $33^{\circ}$. 
rías, servicios públicos, Contraloría, gobiernos regionales, municipalidades, etc. Al efecto, solo basta consultar el Diario Oficial para darse cuenta de la enorme cantidad de normas administrativas reglamentarias que a diario se dictan en nuestro país.

Una cuestión distinta es la discusión que se puede dar respecto de los reparos de constitucionalidad que se puedan hacer frente a las leyes que atribuyen esta potestad normativa a órganos de la Administración distintos del Presidente de la República y que tendremos ocasión de analizar más adelante. No obstante lo anterior, los órganos que tienen esta potestad normativa atribuida por ley la ejercen formalmente bajo la forma de resoluciones, como ocurre con los ministerios, subsecretarías, Contraloría, gobiernos regionales, Dirección General de Aduanas, etc., o con otra denominación que determine la propia ley, como ocurre con las ordenanzas municipales, las cuales se aprueban bajo la forma de decreto alcaldicio. Ahora bien, si la ley le atribuyó al Ministerio de Salud el poder de dictar estas normas, es de toda lógica que la ejerza bajo la forma de resolución.

Entonces, el problema podría ser una eventual inconstitucionalidad de la ley que otorga estas facultades, la cual solo puede ser controlada en casos precisos: control preventivo sujeto a un requerimiento, declaración a posteriori de inaplicabilidad por inconstitucionalidad $\mathrm{y}$, eventualmente, una declaración de inconstitucionalidad con efectos erga omnes. A estos casos se podría agregar el control incidental de constitucionalidad, en donde no hay un pronunciamiento directo sobre la ley, pero sí existe una declaración implícita en tal sentido a propósito del control de los actos de aplicación de la misma, como ha ocurrido en varios casos ${ }^{13}$. En este último supuesto, por disposición expresa de la Constitución, solo pueden ser objeto de control los decretos supremos del Presidente de la República, de manera que por esta vía también es posible hacer un control incidental de la ley que aplican.

En definitiva, el problema no dice relación con la eventual existencia de un decreto supremo encubierto bajo la forma de resolución. La cuestión es que bajo la forma de resolución se dictó por una autoridad inferior un reglamento, potestad que sería -según lo da entender el Tribunal- de competencia exclusiva del Presidente de la República. En buenas cuentas, la ministra de Salud habría invadido las competencias que la Constitución reserva al Presidente al dictar una normativa que es propia de la potestad reglamentaria. Siendo así, la competencia del Tribunal Constitucional se habría extendido más allá del control de los decretos

13 Véase Sentencias del Tribunal Constitucional Rol No 153, de 5 de enero de 1994 (Plan Regulador La Serena-Coquimbo); Rol No 146, de 21 de abril de 1992 (Publicidad carretera I); Rol No 167, de 6 de abril de 1993 (Publicidad carretera II); y Rol No 245, de 2 de diciembre de 1996 (Acceso a las playas). 
supremos, pues estaría comprendiendo las resoluciones de autoridades inferiores que invaden el ámbito de las competencias que la Carta Fundamental ha atribuido de forma exclusiva al Jefe de Estado, lo cual transforma a este órgano en un Tribunal que resguardaría las competencias de la máxima autoridad del país.

La solución no puede ser más inconveniente, pues existe una enorme cantidad de autoridades administrativas que disponen de potestad reglamentaria, tanto en la Administración central como descentralizada. La tesis del Tribunal Constitucional llevada al extremo permitiría afirmar que las resoluciones de contenido normativo que dictan los jefes de servicios no se podrían expedir sino a través de un decreto supremo del Presidente de la República, por comprender materias de su competencia. Además, es posible que su control caiga dentro de las competencias del Tribunal Constitucional, pues en base al principio de primacía de la realidad, estaríamos ante auténticos decretos supremos, pero dictadas por autoridades inferiores. En definitiva, todas las resoluciones dictadas por las autoridades administrativas inferiores podrían ser de conocimiento y resolución por parte de este Tribunal.

Este problema fue en parte resuelto en la Sentencia Rol No 1.035, de 22 de marzo de 2008, en donde se solicitaba la declaración de inconstitucionalidad de un decreto Supremo dictado bajo "la forma de unos oficios y que fueron expedidos con fecha 2 de enero de 2008, aprobando el endeudamiento de la Cuenta de reembolso del Transantiago". En este caso el Tribunal Constitucional señaló que "[...] no se divisa de qué modo podría estimarse, sin alterar la esencia de las cosas, que los oficios ministeriales, mediante los cuales se aprobaron las condiciones de endeudamiento de la Cuenta, constituyen decretos supremos. La teoría de la primacía de la realidad que los requirentes invocan para ello no permite, en caso alguno, arribar a la conclusión que se pretende. Desde luego, porque ella es inconducente para sostener que la Constitución no considere la existencia de resoluciones como un modo válido de regular ciertas materias" ${ }^{14}$. En tal sentido, señala que "[...] si bien la Constitución no define los decretos supremos ni las resoluciones, tampoco los confunde, ni menos prohíbe dictar estas últimas. Así, la Carta Fundamental contempla preceptos que solo se refieren a los decretos supremos, como son los artículos 35 y 93, inciso primero, No 16; mientras otras disposiciones, como es el caso de los artículos 93, No 9 y 99, incisos primero y tercero, y 100, aluden, separadamente, a los decretos y a las resoluciones" 15 . En definitiva el Tribunal explicita lo que anteriormente hemos señalados: "[...]la teoría de la primacía de la realidad por sobre el nominalismo sirvió a esta Magistratura, en la sentencia de fecha

14 Considerando $5^{\circ}$, el destacado es nuestro.

15 Considerando $6^{\circ}$. 
11 de enero de 2007, que citan los requirentes, para considerar que una resolución constituye un decreto supremo de carácter reglamentario, porque, en tal caso, la resolución reunia los elementos configurativos de un acto administrativo de esa indole, es decir, de aquellos que solo puede dictar el Presidente de la República" 16 , así "[...] los oficios que los requirentes pretenden que esta Magistratura considere como decretos supremos, no reúnen, a diferencia del caso que invocan como precedente, ninguno de los requisitos propios del acto administrativo reglamentario" 17 . En definitiva el problema no es si estamos frente a un decreto supremo "por naturaleza", sino frente a normas reglamentarias que deberían ser aprobadas por decreto supremo y no por una simple resolución.

En resumen, si bien el Tribunal Constitucional sostiene de forma implícita la existencia de un concepto sustantivo de decreto suprema, termina resolviendo el problema en base a las competencias que se habría irrogado una autoridad inferior respecto de las que la Constitución asigna al Presidente de la República. Ahora, si bien reconoce que las autoridades administrativas pueden dictar decretos supremos y resoluciones, el problema es que siempre le da a ambas categorías el carácter de actos normativos, al punto de señalar que se tratarían de "actos administrativos reglamentarios".

Los problemas en la calificación jurídica que presenta el Tribunal Constitucional en sus sentencias se debe única y exclusivamente al hecho de que insiste en sostener que los decretos supremos y resoluciones son actos que tienen una naturaleza jurídica predeterminada, sin reparar que se trata de meras formas o procedimientos a través de las cuales se expresan las autoridades administrativa en la vida del Derecho.

\section{2) LA REDUCCIÓN A DOS CATEGORÍAS DE NORMAS: REGLAMENTOS Y CIRCULARES}

Una vez establecida la distinción entre la forma que adoptan los actos de la administración y su contenido, nos corresponde limitar nuestro estudio al conjunto de normas que emanan de los diversos órganos administrativos, para establecer su naturaleza, la forma cómo se relacionan con las demás normas de nuestro ordenamiento y, especialmente, su eficacia o fuerza obligatoria.

Ahora bien, cualquiera que sea la forma que adopten estas normas (decretos supremos, resolución, decretos alcaldicios, circulares, instructivos, etc.), la doctrina distingue dos grandes categorías: los reglamentos y las circulares o instrucciones.

\footnotetext{
16 Considerando $8^{\mathrm{o}}$, el destacado es nuestro.

17 Considerando $9^{\circ}$
} 
Los reglamentos son normas que emanan de órganos de la Administración del Estado y que tienen por objeto desarrollar o complementar lo establecido en las normas legales, cuya fuerza obligatoria vincula a todo órgano público, funcionarios $y$, especialmente, a los particulares, en la medida que sean destinatarios de la misma.

El reglamento tiene una relación particular con el bloque de legalidad. En primer término, emana de una potestad que debe ser expresamente otorgada por la Constitución o la ley. En segundo lugar, una vez ejercida a través de una norma reglamentaria, esta pasa a integrar parte de dicho bloque y, por tanto, constituye el marco de validez de los actos de todos los órganos del Estado, tanto legislativos, jurisdiccionales, administrativos y a toda persona institución o grupo.

Si bien esta última afirmación puede llamar la atención, lo cierto es que un reglamento dictado de acuerdo a la "Constitución y a las normas dictadas conforme a ella" (inciso $1^{\circ}$ artículo 6), vincula a todo sujeto de derecho, incluso al Poder Legislativo, pues si bien los reglamentos deben someterse a la ley, mientras esta no sea objeto de modificación a través de los procedimientos previstos al efecto, cada una de las cámaras parlamentarias han de someterse a los dictados de una gran cantidad de normas reglamentarias, como ocurre en materia de construcción de sus dependencias, de aseo y ornato o del régimen sanitario de los alimentos que se elaboran y consumen en el lugar. Lo mismo sucede con los tribunales de justicia, aunque el reglamento adquiere una mayor relevancia respecto de la función más propia de estos órganos que es la resolución de procesos judiciales, en la medida que puede ser invocada como una auténtica norma decisoria litis. Por último, nos encontramos con los órganos de la Administración, incluyendo a aquella que ha dictado el reglamento (principio de la inderogabilidad singular) y los particulares.

Por su parte, las circulares o instrucciones son normas que también emanan de autoridades de servicio, pero su dictación descansa en otros presupuestos. En primer término, nos encontramos con las facultades que tienen los jefes de servicio para ordenar la buena marcha y funcionamiento del servicio sobre las bases del principio de eficiencia y eficacia en la actuación de los órganos públicos. En segundo lugar, aparece la posición de supraordenación que estos detenta respecto de sus funcionarios dependientes, lo cual les permite dar órdenes generales y singulares para el cumplimiento de sus funciones. Por último, está el margen de discrecionalidad que el ordenamiento jurídico entrega a estas autoridades para adoptar las decisiones más acordes con los principios que han de regir toda gestión administrativa dentro de los márgenes fijados por la ley.

De esta forma, la concepción mayormente aceptada entiende que las circulares o instrucciones son normas que dictan los jefes de servicio en virtud de su potestad jerárquica o de mando, dentro del margen de 
discrecionalidad que le entrega el ordenamiento, para la buena marcha y funcionamiento de la entidad pública.

A partir de estos elementos es posible distinguir con claridad entre los reglamentos y las circulares. En primer lugar, los reglamentos emanan de una potestad atribuida expresamente por la Constitución o la ley, en cambio las circulares son una manifestación de la potestad de mando o jerárquica que tiene todo jefe de servicio. Así, todo jefe de servicio puede dictar circulares, pero no todo jefe de servicio puede dictar reglamentos, salvo que la Constitución o la ley expresamente le atribuyan dicha potestad. En segundo término, las circulares no se publican, pues se dan a conocer a los funcionarios-destinatarios por la vías o canales internos prevista para tal efecto. Por su parte, es conditio sine qua non la publicación para la entrada en vigencia de todo reglamento, tal como lo establece el artículo 48 a) LBPA. Por último, en cuanto a sus efectos, los reglamentos obligan a todo órgano, institución, persona o grupo, mientras que las circulares solo tienen como destinatarios a los funcionarios dependientes. Hay dos razones fundamentales que dan lugar a este aserto. Primero, solo los funcionarios están sometidos a la jerarquía de su jefe de servicio, lo cual no ocurre con los otros órganos del Estado y, especialmente, con los particulares. Segundo, el hecho de que no se publiquen no permite que estas normas sean oponibles y vinculantes a terceros ajenos a la Administración.

Hecha esta distinción, lo cierto es que la cuestión en la práctica no resulta tan fácil de resolver, pues muchas veces nos encontramos con actos de contenido normativo cuya nomenclatura no es uniforme, pues utilizan la denominación de circulares, instructivos, resoluciones, etc. Así, por ejemplo, el director nacional del Servicios de Impuestos Internos tiene la facultad de interpretar administrativamente las disposiciones tributarias, fijar normas, impartir instrucciones y dictar órdenes para la aplicación y fiscalización de los impuestos ${ }^{18}$, lo cual lo hace través de circulares, resoluciones y oficios circulares. El problema se traduce en tratar de establecer en qué casos estamos frente una interpretación, una norma, instrucciones $\mathrm{u}$ órdenes, pues sus alcances pueden variar de forma radical en uno u otro caso, más aún si nos encontramos que sus efectos pueden ir más allá de la Administración, alcanzando incluso a los particulares.

Un primer paso en esta materia es hacer una separación clara entre la forma que adoptan estos actos y la naturaleza de su contenido. En el primer caso, nos encontraremos con decretos supremos, resoluciones, circulares, oficios, etc. Por su parte, en el segundo caso nos podemos encontrar frente a reglamentos, circulares o simples actos administrativos. A su vez,

18 Véase el artículo 70 de DFL No 7, del Ministerio de Hacienda, Ley Orgánica del Servicio de Impuestos Internos y artículo 6o letra a) No 1 del Código Tributario. 
los actos de contenido normativo solo serán los dos primeros, esto es, los reglamentos y circulares, mientras que los actos administrativos tendrían por objeto la aplicación de las normas a casos particulares o concretos. Ahora bien, conforme a lo ya expuesto aparece clara, en principio, la distinción entre reglamento y circulares.

En el caso de las circulares el problema se puede hacer más complejo, en la medida que es posible encontrar un conjunto variopinto de disposiciones administrativas de diversa densidad regulatoria, la cual no es fácil de comprender dentro categorías normativas estrictas. Como bien lo señala Santamaría Pastor "el primer y principal problema que plantean las instrucciones y circulares radica en la extrema polivalencia que estos términos poseen, que, en la práctica, son utilizados como vehículos de los más heterogéneos contenidos" ${ }^{19}$, y en el mismo sentido Sebastián MartínRetortillo señalaba que las circulares (e instrucciones) administrativas enunciadas así, sin más concreción, constituyen un genus complejo que exige inicialmente determinar su contenido ${ }^{20}$.

El tema ha estado fuertemente marcado por una suerte de dogma que niega todo carácter jurídico a las circulares e instrucciones como normas internas. Así ocurre con autores nacionales, como Precth Pizarro ${ }^{21}$, y con buena parte de la doctrina española ${ }^{22}$, italiana ${ }^{23}$ y, especialmente, alemana ${ }^{24}$. Esto se debe a la influencia que ha ejercido la doctrina alema-

19 Véase Santamaría Pastor (1991) 727-728.

20 Véase Martín-Retortillo, Sebastián (1957). "Exceso de poder como vicio del acto administrativo”, Revista de Administración Pública, No 23, p. 152. En especial véase nota 144 de dicho trabajo.

21 Precht Pizarro, Jorge (1989). "Valor jurídico de las directivas presidenciales, programas ministeriales, circulares e instrucciones de servicio", Revista Chilena de Derecho, No 16, p. 469, en donde señala que estas disposiciones son "[...] res interna a la Administración, normas o preceptos técnicos de planificación - programación - presupuesto y que no tienen la fuerza obligatoria bilateral de la norma jurídica". Sin embargo, el punto no aparece tan resuelto, pues afirma de forma contradictoria que "[...] si bien estas normas no son jurídicas (sin perjuicio de que puedan serlo) tienen una importancia capital para el quehacer jurídico de la Administración” (p. 467).

22 Véase Royo-Villanova, Antonio y Segismundo (1965). Elementos de Derecho Administrativo, t. I, 26a ed., Valladolid: Editorial Santarem, p. 58; Garrido Falla, Fernando (1964). Tratado de Derecho Administrativo, t. I, $3^{\text {a }}$ edición, Madrid: Instituto de Estudios Políticos, p. 265; González Pérez, Jesús (1965). El procedimiento administrativo, Madrid: Abella, pp. 608-609; García de Enterría, Eduardo (1958). "Observaciones sobre el fundamento de la inderogabilidad singular de los reglamentos", Revista de Administración Pública, No 27, p. 83; Boquera, Martín (1960). "La publicación de disposiciones generales", Revista de Administración Pública, No 31, p. 72.

23 Véase Orlando, Vittorio E. (1905). "Le fonti del diritto amministrativo italiano", en él mismo: Primo Trattato completo de Dirito Amministrativo italiano, vol. I, Milán: Ed. S.E.L, p. 1.050; Zanobini, Guido (1958). Corso de Diritto amministrativo, Principii Generali, vol. I, 8a ed., Milán: Giuffré, p. 146; Alessi, R. (1960). Sistema istituzionale del diritto amministrativo italiano, $3^{\text {a }}$ ed., Milán: Giuffrè, p. 117.

24 Por todos, véase Fleiner (1933). Instituciones de Derecho Administrativo, Barcelona Madrid - Buenos Aires: Editorial Labor, p. 53. 
na, especialmente de la mano de Laband y Jellinek, al negar todo carácter jurídico a las normas que operan en el ámbito interno de la Administración. En un principio esta calificación se le aplicó a los denominados "reglamentos administrativos", pero se comprendió dentro de las mismas a las circulares e instrucciones, las cuales no serían normas sino "meras operaciones materiales", como dirá Duguit ${ }^{25}$.

La irrupción de las concepciones institucionalistas (Santi Romano) y normativista (Kelsen) llevaron a abonar esta posición desde el ámbito de la teoría general del derecho, con lo cual se reconoció pleno carácter jurídico a las normas de organización, con lo cual se plantea nuevamente el problema respecto de la naturaleza de la circulares.

En razón de lo anterior, la doctrina extranjera y nacional han realizado una serie de distinciones y matices, con el objeto de deslindar con precisión aquellas normas internas que están más cercanas a los reglamentos, respecto de aquellas que contienen políticas, valores, pautas de acción o directrices. Ahora bien, a este respecto Santamaría Pastor distingue entre tres categorías de circulares o instrucciones, considerando el menor o mayor carácter prescriptivo de su contenido. Así, comprende en primer lugar a las circulares informativas, por la cual se transmite a los inferiores datos de hecho relevantes para el ejercicio de su actividad, opiniones o tomas de posición en asunto de importancia política, o recomendaciones no vinculantes acerca del modo de actuación, con una "técnica sutil de dirección". En seguida, nos menciona a las circulares directivas, que son aquellas que imponen "objetivos concretos o standards de eficacia" sin indicar los medios a utilizar. Por último, están las circulares prescriptivas las cuales se dividen, a su vez, en circulares constitutiva de órdenes de servicio y circulares normativas, siendo las primeras de alcance singular (p. ej. orden de inspección urgente), mientras que las segundas "imponen determinadas opciones interpretativas de preceptos legales o reglamentarios, desarrollan algún extremo de una ley o reglamento, establecen un marco de actuación”. Estas últimas son las más cercanas a los reglamentos y se dividen, a su vez, en circulares normativas internas y externas, ya sea que se refieran a cuestiones domésticas de la Administración o que afecten la situación jurídica de terceros como, por ejemplo, aquellas que establecen los criterios a seguir para determinar un impuesto o arancel ${ }^{26}$.

Una camino similar sigue en esta materia Precht, aunque más apegado a la nomenclatura usada en Chile. Al efecto, nos señala que las directivas presidenciales son aquellas que contienen un "conjunto de valores y fines globales que orientarán en un período de tiempo determinado el quehacer político y/o administrativo de la nación" 27 . Como se puede ver,

\footnotetext{
25 Duguit, León (1923). Traité de Droit constitutionnel, t. III, 2a ed., París: Boccard, pp. 362 y ss. 26 Santamaría Pastor (1991) 729.

27 Precht (1989) 469.
} 
esta categoría se corresponde en parte a la figura de las circulares informativas expuestas por Santamaría Pastor. Luego nos seńala que los programas ministeriales contienen "un conjunto de objetivos operacionales (resultados precisos a alcanzar en un lapso prefijado) que debe lograr una unidad u órgano administrativo, sea de la administración centralizada o descentralizada del Estado, vinculada o subordinada a un ministro" ${ }^{28}$. Nuevamente encontramos un correlato entre esta figura y las circulares directivas. Por último, las instrucciones de servicio (circulares, instrucciones, resoluciones, oficios, etc.) son "expresiones de la jerarquía administrativa, esto es, prescripciones que los jefes de servicio dan a los funcionarios colocados bajo su autoridad, en lo que concierne a la administración y la aplicación de las leyes y reglamentos" 29 . En este caso, nos encontramos con las circulares preceptivas del tipo normativo, aunque sin distinguir en cuanto a sus efectos internos o externos.

En cuanto a su fuerza vinculante, la posición de Precht no es del todo clara. En primer término nos señala que son actos indirectos, en la medida que se aplican solo a través de otras medidas administrativas que causan transformaciones en el ordenamiento jurídico ${ }^{30}$. Posteriormente, afirma que pueden ser productoras de efectos jurídicos, al condicionar en cierta manera (sea general o abstracta, sea con un cierto particularismo) los actos administrativos que serán dictados bajo su impulso ${ }^{31}$. Y termina señalando que serían normas técnicas internas de la administración y no normas jurídicas, por lo que son indiferentes a los administrados, salvo algunas excepciones que toma de la jurisprudencia del Consejo de Estado francés ${ }^{32}$.

Si bien parece haber cierta coincidencia entre la distinción hecha por Precht y lo sostenido por Santamaría Pastor, lo cierto es que vamos a optar por la exposición de este último autor, pues los conceptos utilizados por Precht aparecen anclados a la nomenclatura utilizada en nuestro país y no a una categoría dogmática. Además, esto parece ser la razón que no sea tan categórico en sus conclusiones, pues muchas veces estos actos pueden adoptar una determinada forma o denominación, pero su contenido puede ser muy heterogéneo, comprendiendo directrices, objetivos determinados y mandatos muy precisos.

Puestas así las cosas, es evidente que las circulares que nos interesan son aquellas que se pueden calificar de normativas y que buena parte de la doctrina las ha denominado "circulares reglamentarias"33. Más aún, no

Precht (1989) 469.

Precht (1989) 469.

Precht (1989) 468.

Precht (1989) 469.

Precht (1989) 470-471.

Véase, por todos, Baena de Alcázar, Mariano (1965). "Instrucciones y Circulares como 
es posible negar que muchas de estas normas alcanzan en sus efectos a los particulares, estableciendo disposiciones que pueden significar una carga o, en su caso, un beneficio. Así, por ejemplo, una circular que establece los criterios de evaluación que se deben aplicar para la adjudicación de una propuesta pública o de un concurso público; las que establecen los criterios para valorizar una mercancía que ha sido importada; la forma de determinación de la base imponible en los impuestos internos, etc.

En este caso es necesario hacer una distinción, para evitar confundir la forma del contenido. Si el fundamento de la circular se encuentra en una habilitación legal expresa, no cabe duda que nos encontramos ante el ejercicio de la potestad reglamentaria que tiene su fundamento en la norma legal que hace esta atribución. La doctrina espańola se decantó por esta solución, es decir, que la potestad reglamentaria ejercida a través de circulares requiere de una norma habilitante previa ${ }^{34}$, porque en definitiva no estamos ante normas internas en sentido estricto que emanan de la potestad de mando de un jefe de servicio, sino frente a auténticos reglamentos. Ahora bien, esta solución nos traslada a un problema distinto, como es la existencia de una potestad reglamentaria en manos de autoridades inferiores al Presidente de la República, frente a la atribución exclusiva que le otorga la Carta Fundamental sobre esta materia en su artículo 32 No 6 .

Por su parte, si no existe dicha habilitación legal previa, la única posibilidad de dictar una circular de forma válida es a través del ejercicio de la potestad de mando, limitado en este caso al ámbito interno de la Administración, sin que se pueda imponer deberes, cargas u obligaciones fuera de dicha esfera, so pena de cometer una flagrante ilegalidad.

Sin embargo, aun en este caso algunos autores reconocen efectos externos a la circular. Así, Santamaría Pastor sostiene que es claro que la circular tienen eficacia constitutiva, es decir, que tiene la capacidad de crear normas respecto de las relaciones que la Administración mantiene con tercero, sin embargo, "[...] esta normas nuevas creadas por la circular no son oponibles a los terceros; no obligan a éstos como lo hacen los preceptos de las leyes y los reglamentos, por lo que su inobservancia no puede dar lugar a decisiones desfavorables a los mismos" 35 . En el mismo sentido, tampoco estas normas tienen eficacia habilitante, pero constituirán para la Administración parte del marco de la legalidad, cuestión que no ocurre con los particulares. Es decir, "ostentan parcialmente la condición de parámetro de la legalidad de los actos administrativos [...] por cuanto vulnera el principio de jerarquía organizativa, del que la circular es expre-

Fuente del Derecho administrativo", Revista de Administración Pública, No 48, p. 114.

Baena de Alcázar (1965) 126.

Santamaría Pastor (1991) 731. Cabe destacar que en Chile sigue una posición similar Enrique Silva Cimma. Veáse Silva Cimma (2009) 274-275. 
sión concreta: principio al que, por el contrario, no está sujeto el acto del particular ajeno a la organización" 36.

Este último punto es el que no compartimos, pues sostener que el acto administrativo contrario a una circular es inválido para la Administración, a pesar que no se oponga a lo establecido en las leyes o reglamentos, plantea un problema que no es posible resolver, salvo en el caso que el particular alegue dicha "ilegalidad" a su favor o que el tema no se resuelva a través de la nulidad del acto, sino por la responsabilidad del funcionario, cuestión que nos aleja del tema de la validez. La verdad es que es difícil sostener la nulidad de un acto administrativo en estos términos, $y$, menos aún, que la autoridad pueda fundamentar la invalidación del mismo en base a tales argumento. Sin embargo, otra cuestión distinta se plantea en el caso que este acto genere en el particular la convicción de estar actuando conforme a derecho, pero en este caso estamos lejos de sostener la nulidad de acto, sino que estaríamos frente a la conservación de sus efectos.

El Tribunal Constitucional Español en la sentencia 27/1983, de 20 de abril sostuvo que "[...] en nuestro ordenamiento la forma de los actos de la Administración no es relevante en todos los casos para determinar su naturaleza. Así sucede en relación con los supuestos en que los actos administrativos y disposiciones generales de la Administración pueden exteriorizarse en la misma forma, lo que plantea determinar su naturaleza en cada caso concreto". Siguiendo esta regla que, por lo demás, hemos sostenido a lo largo de este trabajo, no cabe sino afirmar que las circulares que contienen normas generales y abstractas; que se dictan previa habilitación legal; que son publicadas y que tienen eficacia respecto de los particulares, en realidad tienen la naturaleza de reglamento, aunque se expresen bajo al forma de circulares, como ocurre con el Banco Central, el Servicio de Impuestos Internos o las superintendencias. En definitiva, el nomen juiris con el cual se designa a una institución o categoría por parte del legislador constituye, en una primera fase, una importante herramienta para establecer la naturaleza jurídica de la misma, aunque se debe reconocer que no es un elemento determinante, pues bien puede ocurrir que el nomen que se utilice no guarde una relación exacta o cabal con el objeto denominado. En buenas cuentas, en derecho las cosas son lo que son y no lo que dicen ser que son, y si estamos frente a una circular de contenido normativo, que se publica y afecta a terceros, es evidente que esta no es una circular propiamente tal, sino que un reglamento. 


\section{3) EL NUdO GORDIANO DE LA CUESTIÓN: LA POTESTAD REGLAMEN- TARIA EN MANOS DE AUTORIDADES INFERIORES AL PRESIDENTE DE LA REPÚBLICA}

Conforme a lo que hemos estado exponiendo, queda claro que en el ámbito de la Administración solo es posible encontrar dos manifestaciones de poderes normativos: aquel que emana de una potestad reglamentaria atribuida expresamente por la Constitución o la ley y aquella que deriva de la potestad jerárquica de los jefes de servicio. Ahora bien, el hecho que las autoridades inferiores dicten normas bajo la forma de circulares no necesariamente determina que estas sean de carácter interno, pues bien podrían tratarse de reglamentos dictados en virtud de una habilitación legal previa.

Puestas así las cosas, el problema que se nos presenta ahora es la cobertura constitucional que tendría una potestad reglamentaria entregada a autoridades inferiores al Presidente de la República, tal como lo venimos señalando anteriormente. Este es un problema que se ha planteado en Derecho comparado, particularmente en el Derecho español a partir de la entrada en vigencia de la Constitución de 1978, la cual atribuyó la titularidad de la potestad reglamentaria solo al gobierno (artículo $97 \mathrm{CE}$ ). Este debate habría quedado zanjado a partir de una distinción entre potestad reglamentaria originaria (atribuida por la Constitución) y potestad reglamentaria derivada (atribuida por la ley). Así, la primera correspondería al gobierno, mientras que la otra se asigna a otras autoridades y requiere de habilitaciones determinadas cuando conllevan la regulación de aspectos que escapan a la organización interna ${ }^{37}$.

En nuestro país existen voces que sostienen la inconstitucionalidad de esta potestad derivada. A este respecto, Eduardo Aldunate afirma que la distribución de competencias regulatorias establecida por la Constitución no puede ser alterada por la ley. "[...] La ley no puede otorgar competencias regulatorias a órganos que quedan fuera del campo de acción jurídica del Presidente, al menos en términos de jerarquía, entendida ésta como potestad de instrucción". Por tanto, concluye que "[...] las leyes que otorgan facultades regulatorias a entes que no cuentan con habilitación constitucional de potestad normativa, y que presentan autonomía jurídica respecto del Presidente de la República, alteran facultades constitucionalmente entregadas al mismo y son, en consecuencia, inconstitucionales" 38 .

37 Véase Moreno Rebato, Mar (1998). "Circulares, instrucciones y órdenes de servicio: naturaleza y régimen jurídico”, Revista de Administración Pública, No 147, p. 162.

38 Véase Aldunate Lizana, Eduardo (2009). "La distribución de potestades normativas en la Constitución: potestades reglamentarias administrativas, autos acordados y facultades del fiscal nacional”, Revista de Derecho de la Pontificia Universidad Católica de Valparaiso, No 33, pp. 374-375. 
En definitiva, Aldunate solo acepta alguna manifestación de potestad reglamentaria derivada en los casos que el respectivo órgano esté bajo la potestad del Presidente de la República, pues a través de instrucciones podrá controlar su ejercicio.

La gran dificultad que enfrenta esta posición es doble. En primer término, la potestad reglamentaria a nivel de órganos inferiores del Presidente de la República se encuentra ampliamente extendida, tanto a nivel central (Dirección General de Aguas, Servicio de Impuestos Internos, Contraloría, etc.), como a nivel de la Administración descentralizada (municipalidades, gobiernos regionales, Banco Central, superintendencias, etc.), cuestión que si bien puede ser objeto de fundados reparos de constitucionalidad, es una realidad que no se puede negar y que se impone a tal punto que -como dice Waline- "cualquier funcionario tiene siempre una cierta tendencia a obedecer antes a una circular, incluso de legalidad dudosa, que a la ley misma [...]".

El segundo problema se presenta con la doctrina sentada por el Tribunal Constitucional respecto del principio de primacia de la realidad y la imposibilidad que las autoridades inferiores puedan dictar reglamentos, so pena de invadir las competencias del Presidente de la República, como lo hemos visto en un apartado anterior (Sentencia Rol No 591, de 11 de enero de 2007). Esta es, por lo demás, la línea seguida por algunos autores, como Alejandro Vergara, quien a propósito de una resolución exenta de la Dirección General de Aguas que contiene normas reglamentarias, señala que se incurre en inconstitucionalidad formal (debiese ser aprobada como decreto supremo) y material (aborda materias reservadas a la potestad reglamentaria, en este caso, del Presidente de la República), "[...] lo cual vicia de nulidad el acto administrativo en cuestión, o al menos, aquellas partes del acto que constituyan verdaderos desarrollos propios de la potestad reglamentaria, por contravenir lo establecido en los artículos $6^{\circ}$ y $7^{\circ}$ de la CPR y en el artículo $2^{\circ}$ de la Ley $N^{\circ} 18.575$, así como las demás disposiciones que regulan el ejercicio de la potestad reglamentaria (artículos $32 \mathrm{~N}^{\circ} 6$ y 35 de la Constitución)"39.

Una posición bastante particular tiene a este respecto Enrique Silva Cimma, pues si bien para este autor no es posible que en virtud de la ley surja una potestad reglamentaria distinta de la que corresponde constitucionalmente al Presidente, no es posible tachar de inconstitucional una ley por esto. En este caso estaríamos ante una potestad reglamentaria delegada pues “[...] en el fondo, cuando un Ente Autónomo dicta normas generales, está usando la potestad reglamentaria presidencial que le ha sido simple-

39 Vergara Blanco, Alejandro (2009). "Los actos administrativos de orden interno. El caso del Manual de procedimientos para la Administración de recursos hídricos de la Dirección General de Aguas", en Ponencia presentada en las XXXIX Jornadas de Derecho Público, p. 10. 
mente delegada" ${ }^{40}$. Lo cierto es que es difícil de comprender esta figura bajo la forma de una delegación, siendo que en realidad estamos ante una habilitación legal que es distinta de la atribuida constitucionalmente y cuyas posibilidad de control y dirección por parte del Presidente de la República aparecen muy limitadas, tal como lo sostiene Aldunate.

Ahora bien, este tema fue tratado en su oportunidad por Arturo Aylwin, quien lo analizó a propósito de los límites de la potestad reglamentaria del Presidente de la República, señalando que solo puede ejercerse dentro del ámbito administrativo que es propio de su competencia $y$, por lo tanto, no rige para regular el ejercicio de funciones de organismos que por mandato constitucional gozan de independencia (Congreso Nacional, Poder Judicial, Tribunal Constitucional, Tribunal Calificador de Elecciones) o autonomía respecto del Poder Ejecutivo (Contraloría, Banco Central ${ }^{41}$.

A este respecto, debemos plantearnos la cuestión a partir del sentido que tiene la potestad reglamentaria presidencial. En efecto, la Constitución nos señala que esta atribución tiene por objeto regular "todas aquellas materias que no sean propias del dominio legal, sin perjuicio de la facultad de dictar los demás reglamentos, decretos e instrucciones que crea convenientes para la ejecución de las leyes". No cabe duda que hay un ámbito que es exclusivo del Presidente respecto de las materias que están fuera del dominio legal, respecto del cual la ley ni otra autoridad puede disciplinar. Cuestión distinta es lo que ocurre con la denominada potestad reglamentaria de ejecución, en donde se produce esta suerte de solapamiento con la potestad reglamentaria de diversos órganos atribuida por la ley. Ahora bien, la interpretación sobre esta materia ha sido la de sostener la exclusividad de la potestad reglamentaria del Presidente de la República frente a las demás autoridades, salvo en aquellos casos en que la propia Constitución haga esta atribución (v. gr. Congreso Nacional, Consejo de Seguridad Nacional, Banco Central, gobiernos regionales y municipalidades), con lo cual se desplaza dicha potestad presidencial.

Sin embargo, bien se podría sostener la interpretación contraria, en la medida que dicha potestad tendría un carácter general frente a las habilitaciones específicas que otorga la ley a otras autoridades. Para este efecto debemos tener presente que la norma constitucional no otorga ni pretende otorgar una potestad exclusiva al Jefe de Estado sobre la material. Del tenor de dicha disposición solo se desprende que a él le corresponde la ejecución de la ley, ya sea que lo haga a través de actos normativos (reglamentos) o actos singulares (actos administrativos), cualquiera sea la forma

Silva Cimma (2009) 195-196.

Aylwin Azócar, Arturo (1984). "Límites a la potestad reglamentaria del Presidente de la República”, Revista Chilena de Derecho, No 11, pp. 449-453. 
que adopten (decretos o instrucciones). Quienes sostienen la idea de una interpretación restrictiva de esta norma no consideran que dicha disposición se refiere a la ejecución de la ley en un amplio alcance, no limitado al ejercicio de la potestad reglamentaria. Así las cosas, no se explica cómo es posible restringir la potestad reglamentaria solo a las competencias del Presidente de la República, mientras que los actos administrativos de aplicación de las leyes también están comprendidos en dicha norma y a nadie se le ocurre sostener que es facultad privativa de dicha autoridad dictarlos. En buenas cuentas, se acepta que las autoridades inferiores dicten actos singulares de aplicación de la ley, mas se rechaza la posibilidad de que pueden dictar reglamentos, sin indicar las razones de dicha distinción. Esto demuestra que la interpretación del artículo 32 No 6 de la Constitución, podría llevar al extremo que todas las potestades públicas administrativas solo deberían ser ejercidas por el Presidente de la República, no dejando margen alguno para que las autoridades inferiores pueden ser titulares de potestades públicas y pueden ejecutar la ley a través de actos administrativos y normas reglamentarias. Creemos que este no es el sentido de la norma constitucional.

Puestas así las cosas, creemos que es posible que el legislador atribuya la potestad reglamentaria a las autoridades administrativas de órganos centralizados y descentralizados, la cual puede coexistir con la potestad general que tiene el Presidente sobre la materia. Sin embargo, es perfectamente posible que nos encontremos frente a potestades concurrentes, cuyo ejercicio puede significar una conflicto normativo real, lo cual demanda de un criterio que pueda resolver esta cuestión. En este sentido, hasta ahora ha operado el principio de jerarquía, en la medida que los reglamentos que emanan del Presidente de la República se imponen a otras autoridades dotadas también de potestad reglamentaria. Esto ha ocurrido en materia de urbanismo y construcción. La Ley General de Urbanismo y Construcción es reglamentada a través de un decreto supremo que contiene la denominada Ordenanza General de Urbanismo y Construcción. Al amparo de dichas disposición se dictan diversos instrumentos de planificación territorial (Plan Regional de Desarrollo Urbano, Plan Regulador Intercomunal, Plan Regulador Comunal y Planes Seccionales). La doctrina está conteste en el sentido que estos planes son auténticas normas reglamentarias, aunque en su dictación intervienen entidades diversas al Gobierno, como son las municipalidades y los gobiernos regionales ${ }^{42}$.

42 Véase Rajevic Mosler, Enrique (1996). "Limitaciones, reserva legal y contenido esencial de la propiedad privada", Revista Chilena de Derecho, No 23; Rajevic Mosler, Enrique (2001). "La planificación urbana en Chile", Revista de Derecho del Consejo de Defensa del Estado, No 3, y Cordero Quinzacara, Eduardo (1998). "La potestad reglamentaria de las entidades territoriales. Los reglamentos regionales, las ordenanzas y los reglamentos municipales", Revista de Derecho de la Universidad Católica del Norte, No 5. 
Ahora bien, una modificación en la ordenanza necesariamente va a repercutir modificando los diversos instrumentos de ordenación territorial, de forma que las contradicciones que pueden existir se resuelvan a favor de la primera. En definitiva, la ordenanza es considerada una norma de mayor jerarquía respecto de los instrumentos de planificación.

También se puede mencionar el caso de la Ley No 20.285, de Acceso a la Información Pública, la cual creó el Consejo para la Transparencia como órgano autónomo y le atribuyó la facultad de dictar "instrucciones generales para el cumplimiento de la legislación sobre transparencia y acceso a la información por parte de los órganos de la Administración del Estado" (artículo 33 d). Sin embargo, el Gobierno dictó el decreto supremo $\mathrm{N}^{\circ} 13$, de fecha 13 de abril de 2009 , y que reglamenta la citada ley, con lo cual condicionó el margen regulatorio que iba a tener la potestad normativa del Consejo a través de dichas instrucciones.

Refuerza el criterio de la jerarquía el fundamento normativo que da origen a la potestad reglamentaria presidencial, la cual descansa en la Constitución, frente a aquella que emana solo de la ley.

Sin perjuicio de lo anterior, existen algunos supuestos en que el principio aplicable será el de la competencia, en los casos en que la Constitución hace una reserva atribuyendo la potestad normativa a determinados órganos. Así, compartimos el criterio que enunciara Arturo Aylwin respecto de los límites a la potestad reglamentaria fundada en la independencia y autonomía de los órganos públicos, como ocurre con el Congreso Nacional, el Poder Judicial, el Tribunal Constitucional, el Tribunal Calificador de Elecciones, la Contraloría General de la República y el Banco Central, al cual se pueden agregar las municipalidades.

\section{4) LA INTERPRETACIÓN ADMINISTRATIVA U OFICIAL}

Un caso particular se nos presenta respecto de una serie de normas que atribuyen a órganos de la Administración la facultad de interpretar las leyes y reglamentos que rigen en un determinado ámbito o sector. Así ocurre, por ejemplo, con la Ley Orgánica del Servicio Nacional de Aduanas, contenida en el Decreto con Fuerza de Ley No 329, de 1979, del Ministerio de Hacienda, la cual establece en su artículo 4 numeral 7 que es atribución del director nacional de Aduanas "interpretar administrativamente, en forma exclusiva, las disposiciones legales y reglamentarias de orden tributario y técnico, cuya aplicación y fiscalización correspondan al Servicio, y en general, las normas relativas a las operaciones aduaneras y dictar órdenes e instrucciones necesarias para darlas a conocer a todos los empleados de Aduanas, que estarán obligados a cumplirlas”. En el mismo sentido, la Ley Orgánica del Servicio de Impuestos Internos, contenida en el Decreto con Fuerza de Ley No 1, de 1980, del Ministerio de Hacienda, establece que al director nacional de este servicio le co- 
rresponde "interpretar administrativamente las disposiciones tributarias, fijar normas, impartir instrucciones y dictar órdenes para la aplicación y fiscalización de los impuestos" (artículo 7 c). Esto se presenta con mayor frecuencia respecto de las superintendencias, a las cuales se les entregan la facultad de interpretar la normativa del sector respecto de los órganos y sujetos que fiscalizan, como ocurre con la Superintendencia de Valores y Seguros (artículo 4 letra A del Decreto Ley No 3.538); la Superintendencia de Salud (artículo 110 No 2 del Decreto con Fuerza de Ley No 1, de 2005, del Ministerio de Salud); la Superintendencia de Pensiones (artículo 30 letra i del Decreto con Fuerza de Ley No101, de 1980, del Ministerio del Trabajo y Previsión Social); y la Superintendencia de Electricidad y Combustible (artículo 3o No 34 de la Ley No 18.410 de 1985), entre otras ${ }^{43}$.

Habitualmente esta facultad interpretativa se expresa a través de resoluciones, circulares o instrucciones, y nos plantean nuevamente el problema sobre el carácter normativo que tendrían y su naturaleza jurídica.

Ahora bien, en nuestra opinión la denominada "facultad interpretativa” es una potestad normativa que se atribuyen los órganos de la Administración, pues no es posible entenderla de una forma distinta. La verdad es que la interpretación que realizan los órganos administrativos debiera limitarse a establecer el sentido y alcance de las leyes y reglamentos que rigen a un determinado sector, no pudiendo en dicho supuesto innovar en el ordenamiento jurídico estableciendo cargas que puedan agravar la situación jurídica de los particulares. Sin embargo, la amplitud de los términos utilizados por el legislador y el recurso a conceptos jurídicos indeterminados, entregan a estos organismos un amplio margen de decisión frente a un abanico más o menos amplio de posibles interpretaciones. En tal sentido, la decisión interpretativa a la cual llegan estas entidades en sus resoluciones, circulares o instrucciones contienen, sin lugar a dudas, el efecto y el carácter de auténticas normas. Por lo demás, la vieja discusión acerca de la naturaleza de la actividad interpretativa cada vez tiende a inclinarse en torno a su carácter volitivo o creador, lo que queda demostrado en este tipo de normas interpretativas. Como bien señalaba Hans Kelsen "si por "interpretación" se entiende la determinación en cuanto conocimiento del sentido del objeto interpretado, el resultado de una interpretación jurídica solo puede ser determinar el marco que expone el derecho por interpretar, y, por lo tanto, el conocimiento de varias posibilidades dadas dentro de ese marco. Por lo tanto, la interpretación de una ley no conduce necesariamente a una decisión única, como si se tratara

43 Sobre la materia véase CAmacho Cepeda, Gladys (2004). "La problemática de la potestad normativa de las Superintendencias", en VV. AA: Actas XXXIV Jornadas de Derecho Público, Santiago: LexisNexis, pp. 423-432. 
de la única correcta, sino posiblemente a varias, todas las cuales -en tanto son cotejadas solamente con la ley que haya de aplicarse- tienen el mismo valor, aunque solo una de ellas se convertirá en derecho positivo en el acto del órgano de aplicación de derecho [...]". Por tal razón concluye que "la interpretación que efectúa el órgano de aplicación del derecho es siempre auténtica. Crea derecho" ${ }^{44}$.

El problema es determinar qué tipo de normas se crean a través de estas facultades interpretativas. En nuestra opinión, la regla general será que estas normas tendrán la naturaleza jurídica de circulares en sentido estricto, es decir, que se aplican en el ámbito interno de la Administración. No obstante lo anterior, también es claro que estas normas alcanzan a particulares, sin embargo, esto es excepcional y se refieren a lo que la doctrina comparada ha denominado administrado cualificado, refiriéndose a aquellos que se encuentran en una suerte de sujeción especial de poder frente a la Administración en razón de su estrecha vinculación con la misma. Esto le permitiría a estos órganos disponer de un conjunto de poderes más intensos que los que puede tener respecto de un administrado simple, permitiendo -incluso- aceptar con mayor flexibilidad la aplicación del principio de legalidad y tolerar una mayor apertura a la regulación reglamentaria respecto de las materias de reserva legal ${ }^{45}$. Dentro de las categorías de los administrados cualificados -sujetos a esta suerte de sujeción especial- se ha incluido tradicionalmente a los funcionarios públicos, el soldado, el enfermo en un hospital público, el estudiante de un colegio público, al interno en un establecimiento penitenciario, al cual se podría agregar a los sujetos particulares que prestan servicios de interés

44 Kelsen, Hans (1982). Teoría Pura del Derecho, México: UNAM, pp. 351-354.

45 El origen de esta distinción se encuentra en el Derecho alemán de fines del siglo XIX, particularmente en la obra de Otto Mayer para quien el principio de legalidad solo rige respecto de las actuaciones externas de la Administración en la medida que signifiquen una intervención a la libertad o propiedad de los ciudadanos, cuestión que no ocurría en el ámbito interno o doméstico, especialmente respecto de los funcionarios, quienes debían aceptar una serie de limitaciones a su libertad sin que fuese necesario la existencia de norma legal previa, extendiéndose posteriormente a una serie de sujetos que se caracterizaban por tener un vínculo más estrecho con la Administración. Véase Forsthoff, Ernst (1958). Tratado de Derecho Administrativo, Madrid: Instituto de Estudios Políticos, p. 185, nota 6. De esta forma, pasaban de una relación de sujeción general frente a la Administración, presidida por el principio de legalidad y propia de todo ciudadano, a una relación de sujeción especial, en donde la legalidad es más flexible y permite intervenir en la esfera jurídica de estas personas rompiendo la regla de la reserva legal. Como bien dice Juan Alfonso Santamaría Pastor “[...] la relación de sujeción especial es un artificio conceptual para excluir la aplicación del principio de reserva de ley en la imposición de limitaciones singulares a la libertad o la propiedad de un sujeto; un título cuya mera invocación permite a la Administración tener manos libres para limitar la libertad o la propiedad sin que una ley previa lo autorice y que, por lo mismo, dada la vaguedad de su contorno conceptual, se presta a graves abusos". Véase Santamaría Pastor (1991) 869. Un trabajo de referencia obligada sobre la materia es el de Gallego Anabitarte, Alfredo (1961). "Las relaciones de sujeción especial y el principio de legalidad de la Administración”, Revista de Administración Pública, No 34, pp. 11-51. 
público y que se encuentran sometidos al control de diversas entidades fiscalizadoras (empresas sanitarias, Isapres, AFP, etc.).

Es bueno tener presente que esta teoría ha ido penetrando en nuestro sistema por la vía de la jurisprudencia del Tribunal Constitucional, el cual ha aceptado que no se aplique el principio de tipicidad a las sanciones administrativas a las cuales están afectos los funcionarios estatales dada la particular posición o intensidad del vínculo que mantiene con el Estado ${ }^{46}$ y que es posible imponer la regulación de los deberes militares por normas administrativas ${ }^{47}$. Sin embargo, sobre el particular hay que tener presente que la doctrina ha reconducido esta teoría, reforzando la vigencia del principio de legalidad, pero reconociendo que no es posible que el legislador pueda definir de manera exhaustiva todas las posibles limitaciones que, en una relación determinada, puede imponer la Administración a la libertad de su personal, labor que ni siquiera un reglamento más detallista puede satisfacer ${ }^{48}$. Así, debe existir legalidad, aunque con una menor exigencia en la concreción de su regulación. Por lo demás, de esa forma lo aceptó el Tribunal Constitucional en la citada sentencia Rol No 747, de 2007. Así las cosas, los particulares sometidos a entidades administrativas fiscalizadoras en razón de los servicios y funciones que cumplen, no estarían en la misma posición que cualquier otro particular, razón por la cual se encontrarían sujetos a este tipo de normas.

Ahora bien, nos queda una segunda cuestión: ¿Es posible que la interpretación administrativa dé lugar a la dictación de normas reglamentarias? En los hechos ha sido así, como ocurre, por ejemplo, con el Compendio de Normas Aduaneras, aprobado por una resolución del director nacional de Aduanas, o con las resoluciones y circulares que dicta el director nacional del Servicio de Impuestos Internos. En algunos casos se ha utilizado un argumento bastante cercano a la figura de las relaciones de sujeción especial para justificar la dictación de estas normas y su obligatoriedad. Así se señala que las normas del Compendio se aplican a toda persona sujeta a la potestad aduanera, mientras que en el caso del Servicio de Impuestos Internos aparecería la potestad tributaria y la figura del contribuyente. Sin embargo, es en estos casos donde muestra su debilidad el concepto de administrado cualificado y de sujeción especial, pues la potestad aduanera se puede ejercer respecto de cualquier persona que ingrese

\footnotetext{
46 Véase Sentencia del Tribunal Constitucional Rol No 747, de 31 de agosto de 2007, considerandos $17^{\circ}$ y ss.

47 Véase Sentencia del Tribunal Constitucional Rol No 468, de 9 de noviembre de 2006, especialmente el voto particular de la ministra Marisol Peńa, quien señala en su considerando tercero que "que lo anterior, confirma que el personal militar se encuentra sometido a una relación de 'sujeción especial', como se afirma en el considerando $8^{\circ}$ de la sentencia, no aplicable o predicable exactamente de otros personales que integran la Administración del Estado".

48 Véase Santamaría Pastor (1991) 867-870.
} 
a territorio nacional, mientras que la potestad tributaria recae sobre cualquier persona que realice lo que se ha denominado un hecho imponible. En definitiva el universo es tan amplio que se desdibuja la línea entre lo que sería una relación de sujeción especial y de sujeción general.

Dado este estado de cosas, no cabe sino afirmar que estamos ante verdaderos reglamentos, los cuales presentan en su gran mayoría serios problemas formales, como es la publicación de su texto en el Diario Ofcial, pues esto constituye una exigencia legal contenida en el artículo 48 a) LBPA, no siendo suficiente la difusión que se haga de las mismas en periódicos comerciales o páginas web. Por tal razón, existe un serio problema respecto de la validez de estas normas.

\section{CONCLUSIONES}

Las normas administrativas han constituido en nuestro sistema una suerte de espacio umbrío que no ha merecido una mayor preocupación en el ámbito de la doctrina y en donde la realidad nos muestra que poco o nada llega el reflejo de las normas constitucionales.

Uno de los primeros problemas que ha planteado su estudio es la relación que hace la doctrina y la jurisprudencia entre denominación que les da el ordenamiento positivo y su naturaleza jurídica, lo cual ha llevado a un esfuerzo mal enfocado que ha tratado de extraer cierta sustancia jurídica a categorías y elementos puramente formales. Esto es lo que ha ocurrido con los decretos supremos y las resoluciones, las cuales son formas de expresión jurídica de las atribuciones de los órganos de gobierno y administración, pudiendo abarcar actos de las más diversas naturalezas, que van desde la dictación de simples actos administrativos hasta la aprobación de normas reglamentarias.

A este respecto sostenemos que las disposiciones administrativas de estricto contenido normativo se pueden reconducir solo a dos categorías: reglamentos o circulares, cuyo fundamento, efectos y régimen jurídico es claramente diverso. En esta misma línea, la regla fundamental que debe adoptar todo operador jurídico para establecer la naturaleza de este tipo de normas es estar a los elementos sustantivos que la determinan antes que al nominalismo que se utiliza para la identificación de las mismas, pues la nomenclatura no tiene la capacidad de alterar la esencia de su contenido.

Otro de los problemas capitales de reconocer la existencia de normas reglamentarias distintas de la que la Constitución asigna al Presidente de la República, son los cuestionamientos de constitucionalidad que se han planteado al respecto, lo cual se sustenta en lo que, en nuestra opinión, es una interpretación errada del artículo 32 No 6 de Constitución, al sostener que dicha atribución sería de carácter exclusiva, salvo las excepciones que la propia Carta Fundamental establece. Por nuestra parte, sostenemos 
que es perfectamente posible que la ley atribuya la potestad reglamentaria a órganos o autoridades inferiores al Presidente de la República. A su vez, en caso de conflicto consideramos que la regla general es la aplicación del principio de jerarquía, salvo las excepciones contenidas en la Constitución en donde opera el principio de competencia.

Por último, somos de la opinión que la interpretación administrativa u oficial se ha de expresar necesariamente en el ámbito normativo a través de disposiciones reglamentarias o circulares, no cumpliendo en la mayoría de los casos las condiciones formales que se exigen para tal efecto, especialmente en lo que dice relación con la publicación de dichas disposiciones.

En definitiva, este trabajo ha tenido por objeto establecer un marco general en la formulación de criterios que nos permitan encajar y comprender un sinnúmero de normas administrativas dentro del ordenamiento jurídico. Ya será objeto de trabajos posteriores analizar esta cuestión a la luz de los diversos subordenamientos que se han ido formando a partir de regulaciones específicas, cuyo mayor contenido se ha de encontrar en las normas administrativas.

\section{BIBLIOGRAFÍA}

- Aldunate Lizana, Eduardo (2009). "La distribución de potestades normativas en la Constitución: potestades reglamentarias administrativas, autos acordados y facultades del fiscal nacional”, Revista de Derecho de la Pontificia Universidad Católica de Valparaíso, No 33.

- Alessi, R. (1960). Sistema istituzionale del diritto amministrativo italiano, $3^{a}$ ed., Milán: Giuffrè.

- Aylwin Azócar, Arturo (1984). "Límites a la potestad reglamentaria del Presidente de la República", Revista Chilena de Derecho, No 11, pp. 449-453.

- Baena de Alcázar, Mariano (1965). "Instrucciones y Circulares como Fuente del Derecho administrativo", Revista de Administración Pública, No 48.

- Boquera, Martín (1960). "La publicación de disposiciones generales", Revista de Administración Pública, No 31.

- Camacho Cepeda, Gladys (2004). "La problemática de la potestad normativa de las Superintendencias", en VV. AA: Actas XXXIV Jornadas de Derecho Público, Santiago: LexisNexis, pp. 423-432.

- Cordero Quinzacara, Eduardo (1998). "La potestad reglamentaria de las entidades territoriales. Los reglamentos regionales, las ordenanzas y los reglamentos municipales", Revista de Derecho de la Universidad Católica del Norte, No 5.

- _ (2007). "La eficacia, extinción y ejecución de los actos administrativos", en VV. AA: Acto y Procedimiento Administrativo, 
Segundas Jornadas de Derecho Administrativo, Valparaíso: Ediciones Universitarias, pp. 109-130.

- Duguit, León (1923). Traité de Droit constitutionnel, t. III, 2a ed., París: Boccard.

- Fleiner (1933). Instituciones de Derecho Administrativo, Barcelona Madrid - Buenos Aires: Editorial Labor.

- Forsthoff, Ernst (1958). Tratado de Derecho Administrativo, Madrid: Instituto de Estudios Políticos.

- Gallego Anabitarte, Alfredo (1961). "Las relaciones de sujeción especial y el principio de legalidad de la Administración”, Revista de Administración Pública, No 34, pp. 11-51.

- García de Enterría, Eduardo (1958). "Observaciones sobre el fundamento de la inderogabilidad singular de los reglamentos", Revista de Administración Pública, No 27.

- Garrido Falla, Fernando (1964). Tratado de Derecho Administrativo, t. I, $3^{\text {a }}$ edición, Madrid: Instituto de Estudios Políticos.

- González Pérez, Jesús (1965). El procedimiento administrativo, Madrid: Abella.

- Gordillo, Agustín (1984). Teoría General del Derecho Administrativo, Madrid: Instituto de Estudios de Administración Local.

- Kelsen, Hans (1982). Teoría Pura del Derecho, México: UNAM.

- Leguina Villa, Jesús (1966). "Legitimación, actos administrativos generales y reglamentos. El valor normativo de las disposiciones organizatorias", Revista de Administración Pública, No 49, pp. 193 y ss.

- Martín-Retortillo, Sebastián (1957). "Exceso de poder como vicio del acto administrativo", Revista de Administración Pública, No 23.

- Martín Retortillo, Lorenzo (1963). "Actos administrativos generales y reglamentos. Sobre la naturaleza de la convocatoria a oposiciones", Revista de Administración Pública, No 40, pp. 225 y ss.

- Meilan Gil, José Luis (1967). La distinción entre norma y acto administrativo, Madrid: Escuela Nacional de Administración Pública.

- Moreno Rebato, Mar (1998). "Circulares, instrucciones y órdenes de servicio: naturaleza y régimen jurídico", Revista de Administración Pública, No 147.

- Orlando, Vittorio E. (1905). "Le fonti del diritto amministrativo italiano", en él mismo: Primo Trattato completo de Dirito Amministrativo italiano, vol. I, Milán: Ed. S.E.L.

- Pierry Arrau, Pedro (2007). "Concepto de acto administrativo en la Ley de Procedimiento Administrativo", en VV. AA: Acto y Procedimiento Administrativo, Segundas Jornadas de Derecho Administrativo, Valparaíso: Ediciones Universitarias, pp. 71-80.

- Precht Pizarro, Jorge (1989). "Valor jurídico de las directivas presidenciales, programas ministeriales, circulares e instrucciones de servicio", Revista Chilena de Derecho, No 16. 
- Rajevic Mosler, Enrique (1996). "Limitaciones, reserva legal y contenido esencial de la propiedad privada", Revista Chilena de Derecho, No 23.

- (2001). "La planificación urbana en Chile", Revista de Derecho del Consejo de Defensa del Estado, No 3.

- Royo-Villanova, Antonio y Segismundo (1965). Elementos de Derecho Administrativo, t. I, 26 a ed., Valladolid: Editorial Santarem.

- Santamaría Pastor, Juan Alfonso (1991). Fundamentos de Derecho Administrativo, Madrid: Ramón Areces.

- Silva Cimma, Enrique (2009). Derecho Administrativo chileno y comparado. Introducción y fuentes, $5^{\text {a }}$ edición, Santiago: Editorial Jurídica de Chile.

- Vergara Blanco, Alejandro (2009) "Los actos administrativos de orden interno. El caso del Manual de procedimientos para la Administración de recursos hídricos de la Dirección General de Aguas", en Ponencia presentada en las XXXIX Jornadas de Derecho Público.

- Zanobini, Guido (1958). Corso de Diritto amministrativo, Principii Generali, vol. I, 8ª ed., Milán: Giuffré. 